\title{
Molecular analysis of clonality in Kaposi's
} sarcoma

Eric Delabesse, Eric Oksenhendler, Celeste Lebbé, Olivier Vérola, Bruno Varet, Ali G Turhan transformants. No definite demonstration of a clonal origin has been provided, mainly because of the lack of a cellular or molecular marker of the lesion.

Clonality is an important characteristic of neoplastic lesions, and absence of clonality is indicative of reactive hyperplasia. A useful marker for clonality is the inactivation pattern of the $\mathrm{X}$ chromosome. In females, one of the two $\mathrm{X}$ chromosomes in each cell is inactivated by methylation and the other one remains active. This methylation occurs in an early stage of embryonic development, at random, and the same methylation pattern is passed to daughter cells in somatic replication. ${ }^{3}$ Thus, in females, normal tissues are composed of cellular mosaics, differing only in which of the two $\mathrm{X}$ chromosomes has been inactivated. In a female heterozygous for an $\mathrm{X}$ linked polymorphism, polyclonal tissues will contain approximately equal numbers of cells in which one or the other polymorphic allele is inactivated. In contrast, in a neoplasm derived from a single somatic cell, all of the tumour cells would retain the same $\mathrm{X}$ chromosome inactivation pattern. ${ }^{5}$

The human $\mathrm{X}$ linked androgen receptor gene (HUMARA) is used widely to assess for clonal patterns of $\mathrm{X}$ chromosome inactivation. A polymorphic short tandem repeat has been identified in the HUMARA gene. More than $80 \%$ of females are heterozygous for the number of CAG trinucleotide repeats in the region. ${ }^{6}$ Polymerase chain reaction (PCR) amplification of a target within the gene that contains flanking $\mathrm{HpaII}$ methylation sensitive restriction endonuclease sites has been described. After digestion of the DNA with $\mathrm{HpaII}$, it is possible to distinguish between polyclonal and clonal cell populations. In a polyclonal population (for example, normal tissue) both maternal and paternal alleles are digested equally and there is an equal reduction of the signal from both alleles after PCR amplification. In contrast, tumour cells arise from a single precursor cell and have the same parental allele inactivated. After digestion and amplification, the signal from the inactive allele remains unchanged, while the signal from the active allele nearly disappears.

The study of clonality in Kaposi's sarcoma using X linked DNA polymorphism is difficult because of a very strong prevalence of the disease in males. ${ }^{17}$ Rabkin et al ${ }^{8}$ have shown that in advanced cases of AIDS related Kaposi's sarcoma, clonal origin could be demonstrated using $\mathrm{X}$ linked DNA polymorphism. More recently, the terminal repeat analysis of $\mathrm{KSHV}$ / coma specimens has stimulated the hypothesis that the sarcoma has a viral origin. ${ }^{2}$ This virus is related to two $\gamma$ herpesviruses, Epstein-Barr virus and Herpesvirus saimiri, which are both immunodeficiency virus (HIV) negative groups, including immunosuppressed transplant recipients and some African and Medi- 
HHV8 DNA from a Kaposi's sarcoma lesion has also suggested a monoclonal expansion of the virus in the Kaposi's sarcoma tumour. ${ }^{9}$ Recently, we have developed a non-radioactive and quantitative clonality assay that allows this analysis to be performed in at least $70 \%$ of an unselected female population. ${ }^{10}$ We had the opportunity to use this methodology to study seven female patients with a diagnosis of Kaposi's sarcoma.

\section{Materials and methods \\ TISSUES}

All seven patients had a skin biopsy (with informed consent) and all analyses were performed with institutional approval. Punch biopsies ( $6 \mathrm{~mm}$ diameter) were performed, using standard procedures, from both a lesion and normal non-adjacent skin. Each biopsy specimen was divided into two samples. One sample was either frozen immediately for further analysis or processed for DNA extraction, and the other was used for confirmation of Kaposi's sarcoma diagnosis by standard histology after staining with haematoxylin and eosin.

In six patients, both normal skin and Kaposi's lesion were analysed in parallel. In one patient (KO), normal skin tissue was not available for analysis, and peripheral blood mononuclear cells were used as a control.

As a control for clonal tissue, a tumour sample from a patient with a diagnosis of cutaneous angiosarcoma or samples of patients with haematological malignancies were used. ${ }^{10}$

\section{HISTOPATHOLOGY}

The various evolutionary stages of 10 Kaposi's sarcoma lesions obtained from seven patients were determinated by haematoxylin and eosin staining. Pathological staging was performed according to Chor. ${ }^{11}$ In the macular or patch phases, small blood vessels dissecting collagen, few extravasated red blood cells, rare plasma, and other inflammatory cells were seen. In the plaque stage, the degree of vascular proliferation involving the whole thickness of the dermis increased with processive lesional evolution. In the advanced tumoural or nodular phase, the entire lesion presented as the proliferation of long spindle shaped cells associated with slit-like blood vessels.

\section{DNA EXTRACTION AND ENZYMATIC DIGESTION}

DNA was extracted from the tumour and normal skin samples using standard procedures. Briefly, samples were digested in $500 \mu \mathrm{l}$ Tris $\mathrm{NaCl}$ EDTA buffer containing $1 \%$ sodium dodecyl sulphate (SDS). Proteinase $\mathrm{K}$ was then added to a final concentration of $100 \mu \mathrm{g} / \mathrm{ml}$ and the sample was kept at $37^{\circ} \mathrm{C}$ overnight. The digestion was pursued for an additional 24 hours with the addition of $40 \mu$ l of proteinase $\mathrm{K}$ $(10 \mathrm{mg} / \mathrm{ml})$ and samples were extracted with TE buffer equilibrated phenol (twice), 1:1 phenol-chloroform (once) and a mixture of 24:1 chloroform-isoamyl alcohol (once). DNA was precipitated in the presence of $2.5 \mathrm{M}$ ammonium acetate and two volumes of ethanol. The pellet was washed with $75 \%$ ethanol and dried.
To perform clonal analysis on informative patient samples, normal and Kaposi's sarcoma DNA were divided into two fractions and one of these was digested with an excess amount of HpaII (10 U) overnight, whereas the other half was left undigested. Both fractions were used for PCR amplification.

\section{PCR AMPLIFICATION}

This analysis was performed according to a clonality assay that we have developed recently. ${ }^{10}$ Briefly, $500 \mathrm{ng}$ of DNA was amplified by PCR with $5^{\prime}$ and $3^{\prime}$ primers $(0.5 \mu \mathrm{M}$ each) encompassing the polymorphic CAG region of the HUMARA gene, HUMARA-C sense which is labelled by fluorescein isothiocyanate (5' GTG CGC GAA GTG ATC CAG AAC $C 3^{\prime}$ ) and HUMARA-C antisense (5 TAC GAT GGG CTT GGG GAG AAC C 3'). After migration on an automatic ABI $373 \mathrm{~A}$ sequence analyser using a $10 \%$ denaturing polyacrylamide gel, fluorescent peaks were quantified with the Applied Biosystems software GeneScan Analysis.

\section{DATA INTERPRETATION}

Amplification of each allele generated a set of tightly clustered multiple bands, including two major product bands and several associated minor bands of lesser intensity. This result is frequently observed after PCR amplification of DNA short tandem repeats. Clonality assessment was based on the major product bands generated from each allele.

A screening gel using DNA extracted from peripheral blood mononuclear cells was performed initially to detect informative patients. Patients were considered heterozygous if PCR amplification of undigested DNA showed two major HUMARA product bands.

In informative patients, analysis of undigested DNA from clonal tissues will still produce two major product bands, as both $\mathrm{X}$ chromosomes are available for amplification. Predigestion of DNA with the methylation sensitive restriction enzyme $\mathrm{HpaII}$ precludes the PCR amplification of the non-methylated allele, permitting amplification of fragments originating from the methylated allele only. Amplification of $\mathrm{HpaII}$ digested DNA from polyclonal tissue will continue to show two major product bands.

The integration analysis of the area under the peaks allowed the quantification of the data. For each sample, either from the normal tissue or the Kaposi's sarcoma lesion, the relative index (RI) value is calculated by dividing the ratio of the two peaks of the HpaII digested sample by the ratio of the two peaks of the undigested sample. The relative corrected index (RCI) is the ratio of the $\mathrm{RI}_{\mathrm{ks}}$ obtained with the Kaposi's sarcoma sample divided by the $\mathrm{RI}_{\mathrm{ns}}$ obtained with the normal skin of the same patient. The final value is inverted if necessary to obtain a value always greater than one. The RCI value is close to one when the sample is polyclonal. In the case of monoclonality, values tend to be infinite.

In previous studies performed in patients with acute leukaemia and myelodysplasia, we 
Table 1 Clinical and pathological data on seven Kaposi's sarcoma (KS) patients

\begin{tabular}{lllll}
\hline Patient & Histopathology of $K S$ & $\begin{array}{l}\text { Duration of } K S \\
\text { months }\end{array}$ & HIV status & $\begin{array}{l}\text { CD4 cell count } \\
\left(\times 10^{6} / \mathrm{l}\right)\end{array}$ \\
\hline BI & Nodule & 6 & Negative & 800 \\
GH & Nodule & 6 & Negative & 972 \\
GI-1 & Nodule & 170 & Negative & 1034 \\
GI-2 & Nodule & & & \\
GI-3 & Nodule & 36 & Negative & 300 \\
KO & Plaque & 2 & Positive & 152 \\
GU & Macule & 24 & Positive & 30 \\
NZ & Plaque & 4 & Positive & 11 \\
MA-1 & Plaque & & & \\
MA-2 & Nodule & & &
\end{tabular}

assessed the sensitivity of our technique, by using mixing experiments with an increasing amount of a known clonal sample (from $5 \%$ up to $95 \%$ ) in a background of a polyclonal sample, both samples being digested with an excess amount of HpaII. In two separate experiments, the value of the RCI increases with the presence of an increasing amount of clonal cells. A $10 \%$ to $20 \%$ contamination with clonal cells could be detected in a polyclonal background as the RCI value ranged between two and three, while a $40 \%$ contamination was associated with a RCI value above 10 (data not shown).

\section{Results}

CLINICAL AND PATHOLOGICAL DATA ON SEVEN KAPOSI'S SARCOMA PATIENTS

Table 1 indicates the clinical and pathological characteristics of the patient population studied. Three patients had HIV associated Kaposi's sarcoma and four patients had classical Kaposi's sarcoma. Kaposi's sarcoma was present for six months or less in four patients and for more than 10 years in patient GI.

Only one case was examinated in the macular stage. Two cases were examinated in the plaque or intermediate phase. In three cases, including one patient for whom three lesions were studied, the lesions were nodular. In the last patient, one lesion was a plaque and another lesion was nodular (fig 1).
CLONALITY ANALYSIS

All seven patients were found to be informative for the HUMARA gene polymorphism and analysable. In six patients, including one patient (MA) with two separate biopsy specimens, a typical polyclonal pattern was demonstrated in the Kaposi's sarcoma tissue with a RCI ranging from 1.1 to 1.7 (fig 2, table 2). In one patient (GI), we had the opportunity to study three separate tumour tissue samples. In all these three biopsy specimens we demonstrated close RCI values ranging from 1.5 to 2.3. However, in this patient the RI in normal skin was 2.3 , indicating a skewing of $\mathrm{X}$ inactivation, and the interpretation of these results in terms of clonality is difficult.

As a monoclonal control, and to validate the ability to detect clonal populations from skin tumours with our assay, we have used DNA extracted from a cutaneous angiosarcoma sample. This analysis showed a typical clonal pattern, with an index value of 19.3 (fig 3 ).

\section{Discussion}

Whether Kaposi's sarcoma is a neoplastic lesion or a reactive process remains controversial. ${ }^{1}$ Most data support the hypothesis that the initial lesion is a reactive hyperplasia: the normal chromosome complement of the spindle cells, ${ }^{12}$ the occasional tumour regression either spontaneously or after reducing the immunosuppression in transplant recipients, ${ }^{13}$ and the dependence on cytokines such as basic fibroblast growth factor, oncostatin $M$, and interleukin 6 (IL-6) for the growth of Kaposi's sarcoma derived cells in vitro. ${ }^{14}$ Usually, in vitro derived Kaposi's sarcoma cells do not have the characteristics of transformed cells. However, at least two Kaposi's sarcoma derived cell lines, KS Y-1 ${ }^{15}$ and $\mathrm{SLK}^{16}$ can induce tumours in nude mice.

Clonality is an important characteristic of neoplastic lesions, and absence of clonality is indicative of reactive hyperplasia. In the absence of a specific clonal chromosomal abnormality, methylation analysis of $\mathrm{X}$ linked genes can give important information with
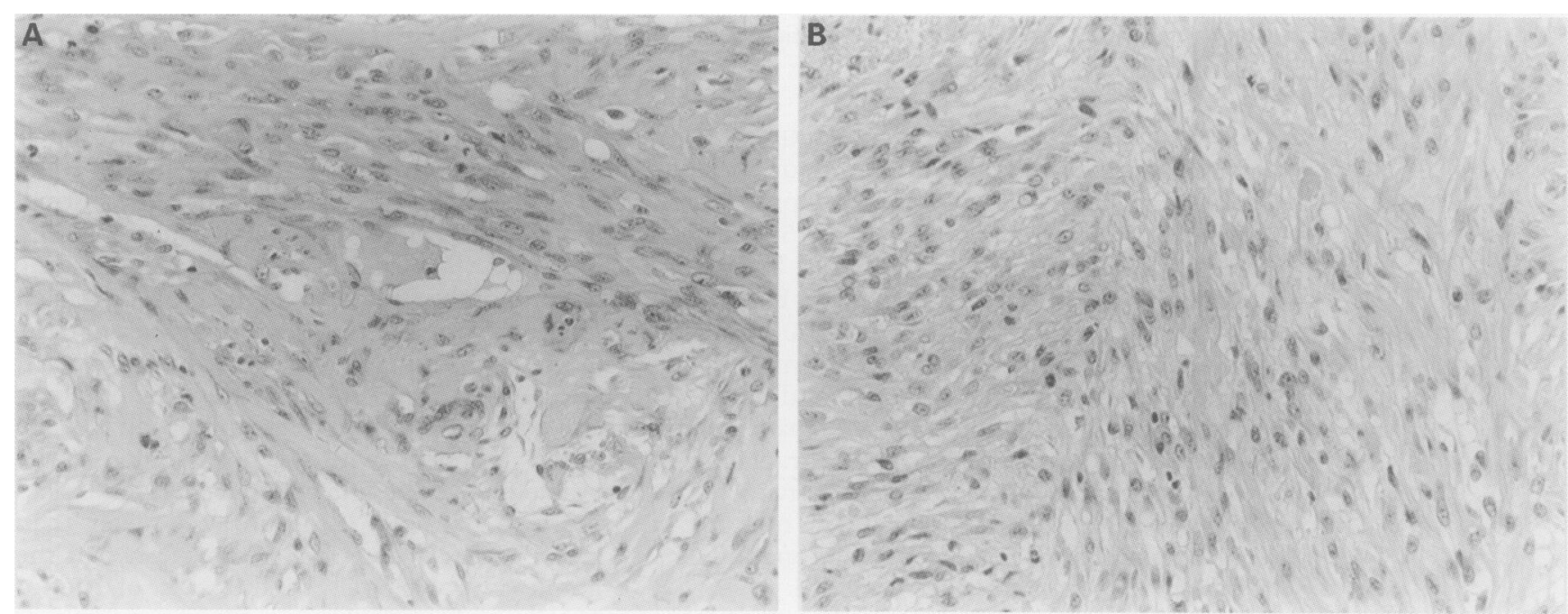

Figure 1 Representative case of Kaposi's sarcoma in an AIDS patient (MA).MA-1, a plaque lesion $(A)$ exhibiting the association of spindle shaped cells and extravasated red blood cells, plasma and other inflammatory cells. $M A-2$, a nodular lesion (B) presenting as a dense proliferation of long spindle shaped cells associated with slit-like blood vessels. (Haematoxylin and eosin, original magnification, $\times 200$.) 
Normal skin

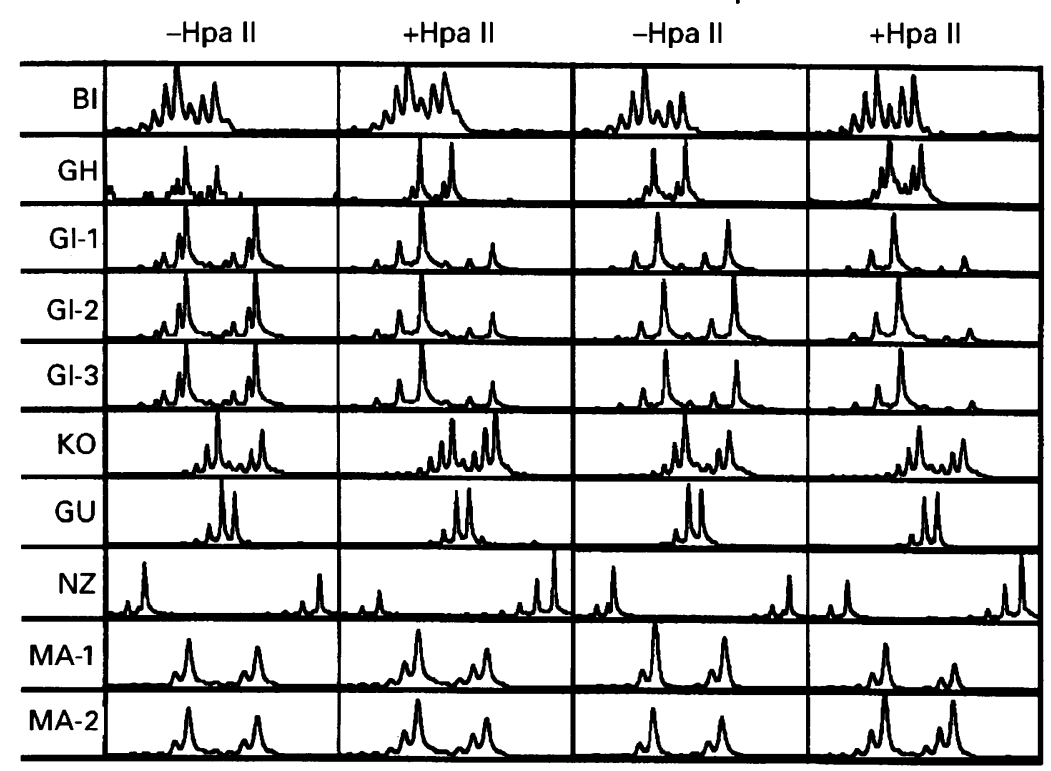

Figure 2 Evaluation of clonality in Kaposi's sarcoma using human androgen receptor (HUMARA) polymorphism analysis in seven female patients. After digestion by HpaII, DNA was amplified from normal skin and from a Kaposi's sarcoma lesion. In most cases the pattern observed after digestion with $H$ paII was very similar in the Kaposi's sarcoma lesion(s) and the normal skin of the same patient. For patient $K O$, in the absence of a normal skin specimen, peripheral blood mononuclear cells were used as a control.

regard to the presence of a clonal cell population in a given sample, provided that an embryologically identical normal tissue has been analysed in parallel as a control. Using this assay, we and others ${ }^{10}{ }^{17}$ have been able to demonstrate the monoclonal nature of human non-lymphoid leukaemic cells, whereas normal

Table 2 Evaluation of clonality in Kaposi's sarcoma using human androgen receptor (HUMARA) polymorphism analysis

\begin{tabular}{llll}
\hline Patient & $R I_{n s}$ & $R I_{k s}$ & $R C I$ \\
\hline BI & 1.2 & 1.5 & 1.2 \\
GH & 0.7 & 1.3 & 1.7 \\
GI-1 & 2.3 & 3.5 & 1.5 \\
GI-2 & 2.3 & 4.3 & 1.9 \\
GI-3 & 2.3 & 5.4 & 2.3 \\
KO & 0.9 & 1.0 & 1.2 \\
GU & 0.8 & 0.9 & 1.2 \\
NZ & 0.3 & 0.5 & 1.7 \\
MA-1 & 1.3 & 1.0 & 1.4 \\
MA-2 & 1.3 & 1.4 & 1.1
\end{tabular}

RI, relative index; $R i_{n s}$, relative index of normal skin; $R_{k s}$, relative index of Kaposi's sarcoma lesions; RIC, relative corrected index (ratio of $\mathrm{RI}_{\mathrm{ks}}: \mathrm{RI}_{\mathrm{ns}}$ ).

When RCI is close to 1 , the sample is polyclonal. In the case of monoclonality, values tend to be infinite. For patient $\mathrm{KO}$, in the absence of a normal skin specimen, peripheral blood mononuclear cells were used as a control.

-Hpa II

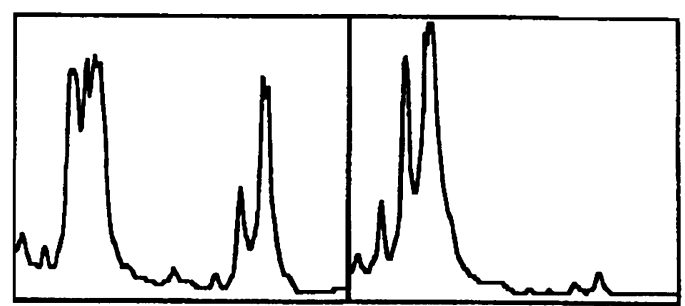

Figure 3 Evaluation of clonality in a cutaneous angiosarcoma using HUMARA polymorphism analysis. DNA from the lesion was amplified directly (left) and after digestion by HpaII (right). After digestion and amplification, the signal from the inactive allele remains unchanged, while the signal from the active allele nearly disappears. cells from the same patients exhibited a normal polyclonal pattern.

In Kaposi's sarcoma, the only available study included three patients with AIDS related nodular Kaposi's sarcoma who showed a clonal pattern of the sarcoma lesion using HUMARA polymorphism analysis. ${ }^{8}$ Eight women had undergone cutaneous biopsy but only three specimens were selected for analysis on the basis of less than $20 \%$ contaminating normal cells after examination of the section by light microscopy. This selection may have favoured sarcomatous lesions observed in patients with long standing Kaposi's sarcoma lesions. Our patient population was different from that included in this series. First, in four of the seven patients, Kaposi's sarcoma was not related to HIV infection, and in four cases, the lesions had been present for less than six months. Second, four of 10 lesions studied were macules or plaques, and in these lesions the proportion of spindle cells did not exceed $20 \%$. However, the six other lesions were nodular with a proportion of spindle cells exceeding $70 \%$ in four of them.

The present study presents indirect molecular evidence that most cells involved in the Kaposi's sarcoma lesion are polyclonal. The most likely explanation for a false polyclonal pattern in a clonal tissue is the contamination of the biopsy specimen with normal cells. We attempted to minimise this bias by evaluating the percentage of spindle cells by careful classical morphological examination of adjacent sections. The presence of more than $70 \%$ spindle cells in four out of 10 specimens suggests that a clonal proliferation of these cells could have been detected. In these four lesions (BI, GH, GI-2, MA-2) the RCI was below two, indicative of a polyclonal cell population. In our experience, and as demonstrated by Enamoto et al, clonality can be assessed with the HUMARA technique when monoclonal cells constitute $>20 \%$ of the total cell population. ${ }^{18}$ Furthermore, using the same technique, the analysis of a cutaneous angiosarcoma demonstrated unequivocal clonality of the lesion.

It has been demonstrated by PCR in situ hybridisation that $\mathrm{KSHV} / \mathrm{HHV} 8$ is localised to the endothelial cells that line the irregular vascular slits and to some of the perivascular spindle shaped cells seen in Kaposi's sarcoma lesions. ${ }^{1920}$ These results suggest that the first critical event of Kaposi's sarcoma pathogenesis could be the infection of the target cell with $\mathrm{KSHV} / \mathrm{HHV}$. The finding by Russo et $\mathrm{al}^{9}$ that $\mathrm{KSHV} / \mathrm{HHV} 8$ is clonal in a Kaposi's sarcoma specimen may represent the clonal evolution of an advanced lesion or the presence in the lesion of both clonal infected cells and proliferating uninfected cells.

The viral infection could induce proliferation of the spindle cells through autocrine and/or paracrine production of cellular cytokines or through the expression of viral genes, homologues of cellular genes involved in cell proliferation (vIL-6, G-protein coupled receptor $^{91}$ or transformation (vBcl-2, vCyclin), ${ }^{22}$ and of viral homologues of chemo- 
kines (macrophage inflammatory protein: vMIP-I, vMIP-II) $)^{24}$ leading to the formation of tumoural lesions. In a later stage or after a new oncogenic event, clonal selection may contribute to the development of more agressive tumoural nodules. With such a scenario, very similar to that observed in Epstein-Barr virus associated lymphoproliferative disorders, a polyclonal proliferation of the spindle cells could be followed by clonal restriction.

The authors thank Dr Françoise Timsit for referring some of the patients. This work was supported by a grant from INSERM.

1 Tappero JW, Conant MA, Wolfe SF, Berger TG. Kaposi's sarcoma. F Am Acad Dermatol 1993,28:371-95.

2 Chang Y, Cesarman E, Pessin MS, Lee F, Culpepper JC, Knowles DM, et al. Identification of herpesvirus-like DNA sequences in AIDS-associated Kaposi's sarcoma. Science 1994,266:1865-9.

3 Vogelstein B, Fearon ER, Hamilton SR, Feinberg AP. Use of restriction fragment length polymorphisms to determine
the clonal origin of human tumours. Science 1985,227:642the

4 Vogelstein B, Fearon ER, Hamilton SR, Preisinger AC, Willard HF, Michelson AM, et al. Clonal analysis using recombinant DNA probes from the X-chromosome. Cancer Res 1987,47:4806-13.

5 Busque L, Gilliland DG. Clonal evolution in acute myeloid leukemia. Blood 1993;82:337-42.

6 Allen RC, Zoghbi HY, Moseley AB, Rosenblatt HM, Belmont JW. Methylation of Hpall and Hhal sites near the polymorphic CAG repeat in the human androgen-receptor gene correlates with $\mathrm{X}$ chromosome inactivation. $A m \mathrm{f}$ gene correlates with X chrom

7 Lassoued K, Clauvel JP, Fegueux S, Matheron S, Gorin I, Oksenhendler E. AIDS-associated Kaposi's sarcoma in Oksenhendler E. AIDS-associated Kap
female patients. AIDS 1991;5:877-80.

8 Rabkin CS, Bedi G, Musaba E, Sunkutu R, Mwansa N, Sidransky D, et al. AIDS-related Kaposi's sarcoma is a clonal neoplasm. Clin Cancer Res 1995;1:257-60

9 Russo J, Bohenzky RA, Chien MC, Chen J, Yan M, Maddalena $\mathrm{D}$, et al. Nucleotide sequence of the Kaposi sarcomaassociated herpesvirus (HHV8). Proc Natl Acad Sci USA 1996;93:14862-7.

10 Delabesse E, Aral S, Kamoun P, Varet B, Turhan AG. Quantitative non-radioactive clonality analysis of human leukemic cells and progenitors using the human androgen receptor (AR) gene. Leukemia 1995;9:1578-82.

11 Chor PJ, Santa Cruz DJ. Kaposi's sarcoma: a clinicopathologic review and differential diagnosis. $₹$ Cutan Pathol 1992;19:6-20.

12 Fukunaga M, Silverberg SG. Kaposi's sarcoma in patients with acquired immune deficiency syndrome. A flow cytometric DNA analysis of 26 lesions in 21 patients. Cancer 1990;66:758-64.

13 Brooks JJ. Kaposi's sarcoma: a reversible hyperplasia. Lancet 1986;ii:1309-11.

14 Ensoli B, Barillari G, Gallo RC. Cytokines and growth factors in the pathogenesis of AIDS-associated Kaposi's sarcoma. Immunol Rev 1992;127:147-55.

15 Lunardi-Iskandar Y, Gill P, Lam VH, Zeman RA, Michael F, Mann DL, et al. Isolation and characterization of an immortal neoplastic cell line (KS Y-1) from AIDSassociated Kaposi's sarcoma. F Natl Cancer Inst 1995;87: 974-81.

16 Herndier BG, Werner A, Arnstein P, Abbey NW, Demarti $F$, Cohen RI, et al. Characterization of a human Kaposi's sarcoma cell line that induces angiogenic tumours in animals. AIDS 1994;8:575-81.

17 Busque L, Zhu J, DeHart D, Griffith B, Willman C, Carroll $R$, et al. An expression based clonality assay at the human androgen receptor locus (HUMARA) on chromosome $\mathrm{X}$. Nucleic Acids Res 1994;22:697-8.

18 Enamoto $T$, Fujita $M$, Inoue $M$, Tanizawa $O$, Normura $T$, Shroyer KR. Analysis of clonality by amplification of short tandem repeats: carcinomas of the female reproductive tract. Diagn Mol Pathol 1994;3:292-7.

19 Boshoff C, Schulz TF, Kennedy MM, Graham AK, Fisher C, Thomas A, et al. Kaposi's sarcoma-associated herpesvirus infects endothelial and spindle cells. Nat Med 1995;1:1274-8.

20 Huang YG, Li JJ, Zhang WG, Feiner D, Friedman-Kien AE Transcription of human herpesvirus-like agent (HHV-8) in Kaposi's sarcoma. $\mathcal{f}$ Clin Invest 1996;97:2803-6.

21 Arvanitakis L, Geras-Raaka, Varma A, Gershengorn MC Cesarman E. Human herpesvirus KSHV encodes a constitutively active G-protein-coupled receptor linked to cell proliferation. Nature 1997;385:347-50.

22 Sarid R, Sato T, Bohenzky RA, Russo J, Chang Y. Kaposi's sarcoma-associated herpesvirus encodes a funtional Bcl-2 homologue. Nat Med 1997;3:293-8.

23 Chang Y, Moore PS, Talbot SJ, Boshoff CH, Zarkowska T, Godden-Kent $\mathrm{D}$, et al. Cyclin encoded by KS herpesvirus. Nature 1996;382:410.

24 Moore PS, Boshoff C, Weiss RA, Chang Y. Molecular mimicry of human cytokine and cytokine response pathway genes by KSHV. Science 1997;274:1739-44. 